\title{
Uterine Natural Killer Cells in a Three-Dimensional Tissue Culture Model to Study Trophoblast Invasion
}

\author{
Christine Helige, Gabriele Hagendorfer, Josef Smolle, and Gottfried Dohr \\ Institute of Histology and Embryology (CH, GH, GD) and Department of Dermatology and Venerology (JS), \\ University of Graz, Graz, Austria
}

\begin{abstract}
SUMMARY: The high numbers of $\mathrm{CD}^{+} 6^{+}$cells with natural killer (NK) functions present in the uterine mucosa during the late secretory phase of the menstrual cycle and during early pregnancy have been considered to be implicated in implantation and in the regulation of trophoblast invasion. A three-dimensional organ culture model was used to study the interactions of these uterine NK cells with Jeg-3 and BeWo choriocarcinoma cells as a model of the invasive trophoblast. For this purpose, fragments of endometrial and decidual tissue were put in close contact with multicellular spheroids of choriocarcinoma cells in small silicon funnels. After the formation of stable contacts, the confrontation cultures were transferred to spinner flasks, cultivated for up to 6 days, and prepared for immunohistochemistry. During 2 days of cocultivation, the first cells started to move forward into the stromal component of the confrontation culture as demonstrated by staining of the choriocarcinoma cells using anti-human cytokeratin. Invasion advanced until, after a total of 6 days, some choriocarcinoma cells had already penetrated deeply into the host tissue. After a cultivation period of 1 week, both the endometrial and decidual tissue fragments still contained several CD56 ${ }^{+}$ uterine NK cells, and some of them expressed the proliferation-associated marker Ki-67 without any exogenous activation. A few $\mathrm{CD}{ }^{+}$cells were found directly at the invasion front, as well as between the choriocarcinoma cells. These cells also contained the cytolytic granule protein perforin indicating a migration of NK cells with cytolytic potential toward the potentially invasive cells. In conclusion, this human system closely resembles the in vivo conditions during trophoblast invasion and provides an appropriate in vitro model for studying dynamic processes involving various cell types during trophoblast invasion at the experimental level. Moreover, it enables us to study the effects of cytokines and growth factors that possibly regulate trophoblast invasion. (Lab Invest 2001, 81:1153-1162).
\end{abstract}

$T$ he biological mechanisms involved in embryo implantation as well as the factors regulating trophoblast invasion are far from being completely understood. The interactions of trophoblast cells with the decidual tissue include the phenomena of cell adhesion, proteolytic tissue degradation, immunoregulation, and others. The immunology of the fetomaternal interface has been studied extensively, particularly using sections derived from first trimester placenta or by the phenotypic analysis of isolated cells. The maternal part of the placenta consists of stromal cells, epithelial glandular cells, blood vessels, and numerous bone-marrow-derived cells, the main proportion of which are large granular lymphocytes with the phenotype $\mathrm{CD}^{-} \mathrm{CD}^{-} 6^{-} \mathrm{CD}_{56}{ }^{+}$and natural killer (NK) functions (Bulmer et al, 1991; Gudelj et al, 1996; King, 2000; King et al, 1989; 1991; 1998; Starkey et al, 1988). Other cells include macrophages (20\%) and T cells (approximately 10\%). These high

Received May 21, 2001.

The study was supported by the Kamillo Eisner-Foundation, Schaffhausen, Switzerland, and by the Franz Lanyar-Foundation, Graz, Austria.

Address reprint requests to: Dr. Christine Helige, Institute of Histology and Embryology, University of Graz, Harrachgasse 21, A-8010 Graz, Austria. E-mail: christine.helige@kfunigraz.ac.at numbers of NK-lineage cells are found during the late secretory phase of the menstrual cycle and during the first trimester of normal gestation and decrease, as pregnancy proceeds, until they become virtually undetectable at term. Because decidual lymphocytes produce various cytokines (Deniz et al, 1996, Jokhi et al, 1997), they are considered to play a crucial role in initiating and maintaining decidualization, in implantation and in the regulation of trophoblast invasion (King, 2000; King et al, 1998). The expression of cytolytic granule proteins implies that these cells are capable of effector functions (Gudelj et al, 1997; King et al, 1993; Lin et al, 1991; Rukavina et al, 1995), although they do not make use of their cytolytic potential during normal pregnancy.

Studies of the immunoregulation of trophoblast invasion are hampered by the difficulty of duplication of the specialized uterine environment in vitro. Various tissue culture models have been established to study the early stages of embryo implantation in mammals. Most of them use two-dimensional extracellular matrix (eg, Damsky et al, 1994; Hamilton et al, 1998; Morgan et al, 1998) or monolayers of endometrial epithelial cells (Lindenberg et al, 1985) as a substrate for trophoblast invasion. However, in several of these experiments, immunological studies cannot be performed because immunocompetent cells are lacking in these systems. Three-dimensional multicellular models offer many tissue characteristics that cannot be obtained 
using monolayer or suspension cultures and provide more reliable data than two-dimensional systems. Explants of endometrial (Bersinger et al, 1993; Kliman et al, 1990) or decidual tissue (Vicovac et al, 1993, 1995) have already been used as a substrate for trophoblast invasion, although immunological aspects are not included in these studies. A three-dimensional tissue culture model, originally established for studies on tumor invasion (Mareel et al, 1979), has been modified for studies on embryo implantation. The model uses confrontation cultures composed of rounded fragments of luteal-phase human endometrial tissue and multicellular spheroids of choriocarcinoma cells as a model of the invasive trophoblast (Grümmer et al, 1990, 1994).

In the present study, this system is applied to study the interactions of human uterine NK cells with invasive choriocarcinoma cells at the experimental level. The method for the formation of confrontation cultures has been modified and improved. In addition to endometrial tissue as a substrate for trophoblast invasion, tissue fragments derived from human first trimester decidua parietalis are used as well.

\section{Results}

\section{Rounded Fragments of Human Endometrium}

After 4 days in spinner culture the human mid-secretory endometrial tissue fragments were rounded at the edges and showed a smooth surface. The stroma was well preserved wherever the spheroidal size of $800 \mu \mathrm{m}$ was not exceeded. The organotypic architecture was represented by the presence of typical glands and numerous NK-lineage cells in the stroma (Fig. 1a). They were almost evenly distributed on the tissue sections, although there were some spheroids showing more NK cells than the others, which was in accordance with the distribution of $\mathrm{CD}_{56}{ }^{+}$cells found in the freshly embedded luteal-phase endometrium. In general, the number of $\mathrm{CD}^{+} 6^{+}$cells in the tissue considerably decreased after cultivation, even though hormones were present in the culture medium (Fig. 2). A few $\mathrm{CD}^{+}{ }^{+}$cells coexpressed the $\mathrm{Ki}-67$ antigen, indicating that those cells were able to proliferate within cultivated endometrial tissue without any exogenous stimulus by cytokines. Rounded fragments of endometrium also contained
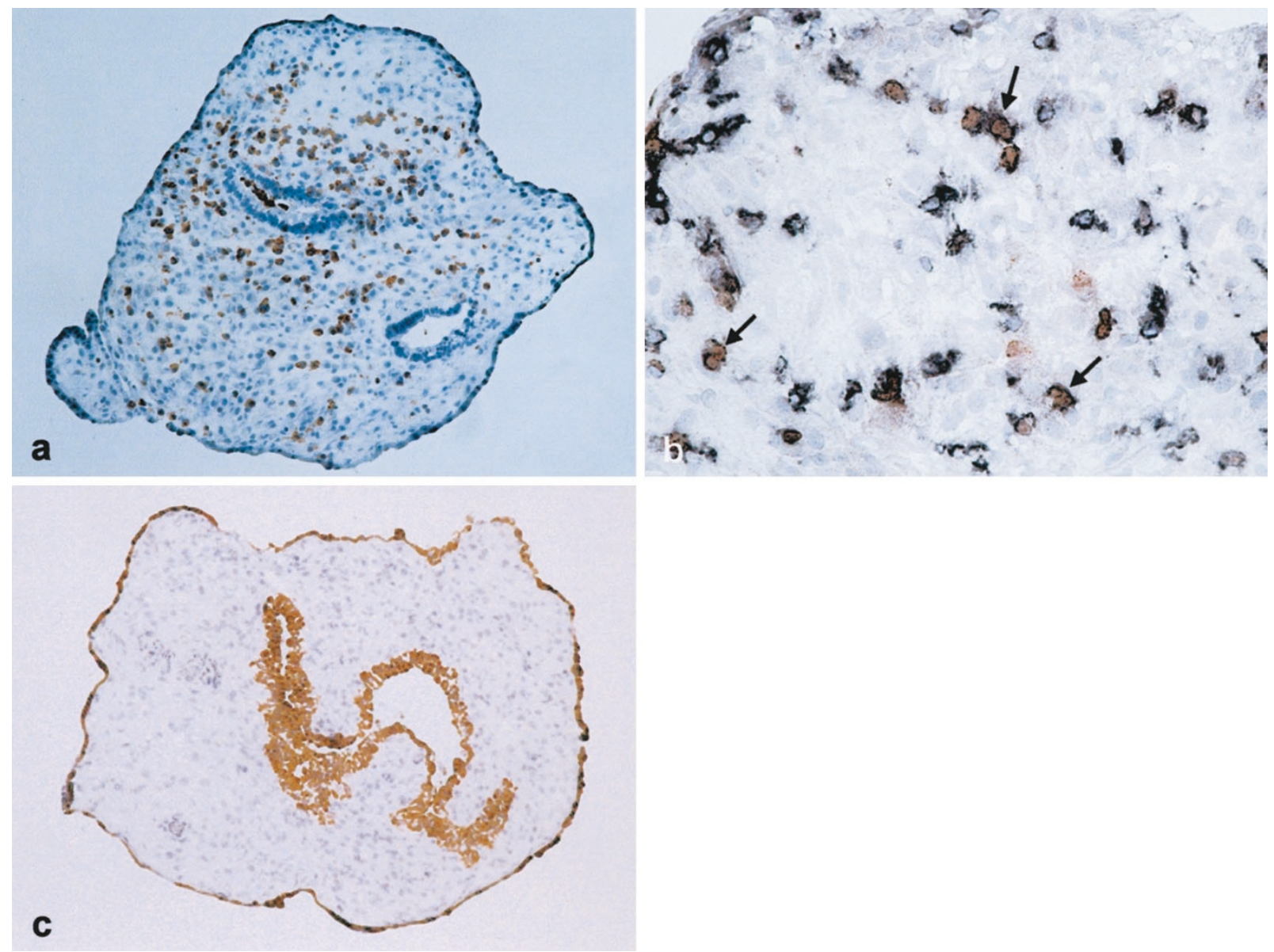

Figure 1.

Substrate of trophoblast invasion. Cryostat sections from rounded fragments of luteal-phase endometrial tissue (a) and rounded fragments of first trimester decidua parietalis ( $b$ and $c$ ) after 4 days of cultivation. a, Staining with anti-human CD56. Numerous natural killer (NK) cells are preserved in the cultivated tissue fragment. b, Double-staining with anti-human CD56 (black) and anti-human Ki-67 (red) demonstrating proliferation of certain NK cells (arrows). c, Staining with anti-human cytokeratin (clone MNF116). Smooth cytokeratin ${ }^{+}$surface and glands, however, show no signs of trophoblast invasion. Original magnification: a and c, $\times 250 ; b$, $\times 1000$. 


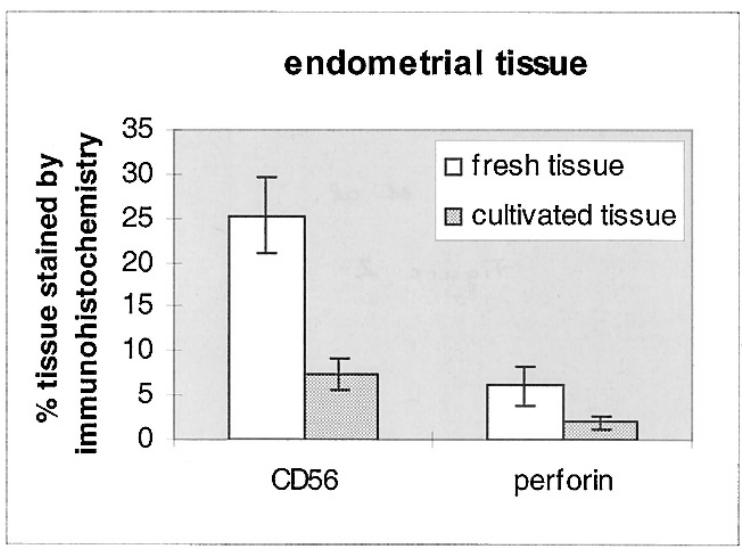

Figure 2.

Evaluation of the expression of CD56 and perforin by uterine NK cells by automated image analysis after immunohistochemical staining of tissue sections. $\square, \square$, mean values; $\perp$, SEM.

cells expressing the cytolytic granule protein perforin, although in a reduced number compared with fresh endometrial tissue (Fig. 2). The percentage of $\mathrm{CD}^{+} 6^{+}$ and perforin ${ }^{+}$cells varied considerably among the tissues derived from the different women.

\section{Rounded Fragments of Human First Trimester Decidua Parietalis}

In the stroma of cultivated rounded fragments of human first trimester decidua parietalis, numerous $\mathrm{CD}^{+} 6^{+}$NK cells were observed. In comparison with endometrial tissue fragments, the decrease in the number of $\mathrm{CD}^{+} 6^{+} \mathrm{NK}$ cells after cultivation was less pronounced in decidual tissue (data not shown). Double-labeling with anti-CD56 and anti-Ki-67 antibodies indicated that decidual NK cells were also able to proliferate within cultivated tissue fragments without any activation by exogenous cytokines (Fig. 1b). In decidual tissue fragments, more $\mathrm{CD}^{+}{ }^{+} \mathrm{NK}$ cells coexpressed the Ki-67 antigen, compared with NK cells in cultivated endometrium. Moreover, like NK cells in the endometrium, decidual NK cells also retained their capacity to express the cytolytic granule protein perforin after cultivation for several days. The expression of both CD56 and perforin by lymphocytes was considerably higher in cultivated decidual tissue fragments compared with that found in cultivated nonpregnant endometrium.

Cultivated decidual tissue fragments, derived from decidua parietalis, were rounded at the edges and were covered by a flat surface epithelium comparable with endometrial tissue fragments after spinner culture. Apart from numerous glands, no cytokeratinpositive cells were found in the stroma, indicating no invasive cells resulting from trophoblast cells possibly having penetrated the decidual tissue before confrontation culture (Fig. 1c).

\section{Confrontation Cultures of Human Endometrium and Human Choriocarcinoma Cells}

In a first set of experiments, rounded fragments of endometrial tissue, approximately $800 \mu \mathrm{m}$ in diame- ter, were set in close contact with multicellular spheroids of choriocarcinoma cells, $300 \mu \mathrm{m}$ in diameter, on top of a semi-solid agar medium. To force adhesion, cocultivation of both confrontation partners on top of a semi-solid agar medium during the initial period of attachment had to be performed without culture medium. The procedure resulted in a drying out of the major part of the cultures. The problem occurred even at $95 \%$ relative humidity in the $\mathrm{CO}_{2}$ incubator. Moreover, under those experimental conditions, less than half of the confrontation pairs remained attached after the addition of culture medium. Therefore, the method for the production of confrontation cultures was modified and improved (see "Materials and Methods").

Applying our new method for confrontation culture, a high percentage of the multicellular spheroids of choriocarcinoma cells adhered to the surface of the rounded fragments of endometrial tissue in the silicon funnels. After the formation of stable contacts, the confrontation cultures were transferred to $25-\mathrm{ml}$ spinner flasks, which enabled a good supply of nutrients. Nevertheless, there were some problems with a clustering of the cultures at the bottom of the flasks, which was due to the streaming conditions present in the culture flasks. Therefore, the ideal position of the magnetic rod had to be determined before cultivation.

In general, Jeg-3 cells were more invasive than BeWo cells in the three-dimensional tissue culture model. Within 2 days of cocultivation, the first Jeg-3 cells started to move forward into the stromal component of the confrontation culture as demonstrated by immunohistochemical staining of the choriocarcinoma cells using anti-human cytokeratin (Fig. 3, a and b). After 4 days of confrontation culture, invasion advanced by the protrusion of fingers of the choriocarcinoma cells into the stroma (Fig. 3, c and d), and after a total of 6 days, some single cells had already invaded deeply into the host tissue (Fig. 3, e and f).

BeWo cells grew out at the surface of the endometrial spheroids completely surrounding the host tissue after 4 to 5 days of coculture without any distinct signs of invasion (data not shown). The endometrial tissue component contained several $\mathrm{CD}^{+} 6^{+}$NK-lineage cells. The expression of this cell surface marker was maintained in tissue culture over a period of more than one week.

\section{Confrontation Cultures of Human Decidua and Human Choriocarcinoma Cells}

The invasive activity of both choriocarcinoma cell lines in the decidual tissue fragments was comparable to that observed in the confrontation cultures with endometrial tissue fragments. The decidual component of the cocultures also contained numerous $\mathrm{CD}^{2} 6^{+}$cells, which were almost evenly distributed in the stroma (Fig. 4a). Double-staining using anti-human cytokeratin and anti-human CD56 showed that some CD56 ${ }^{+}$ NK-lineage cells were present directly at the borderline between both components of the confrontation culture. In addition, a few NK cells were found between the BeWo cells, indicating a migration of these 

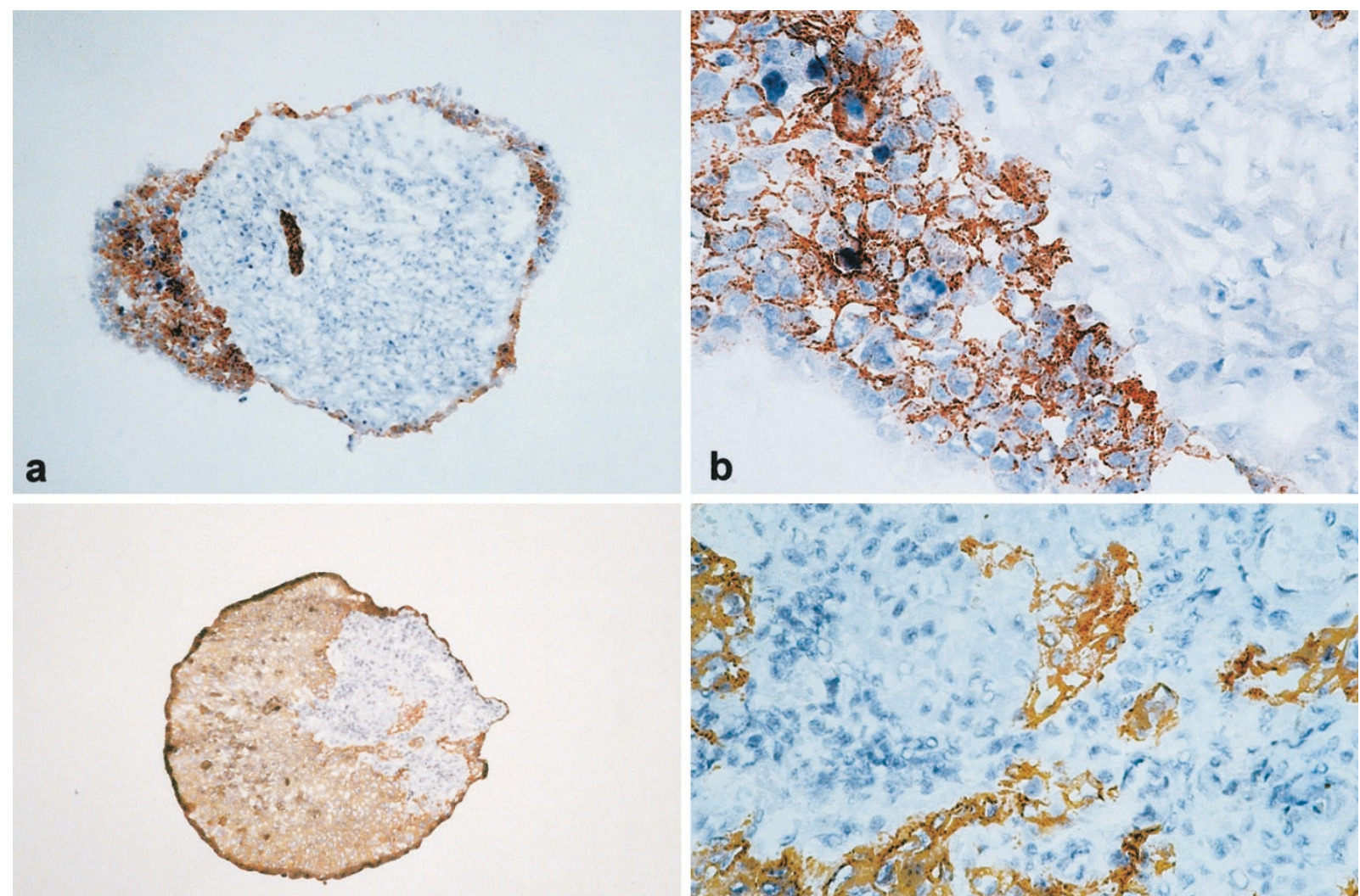

C
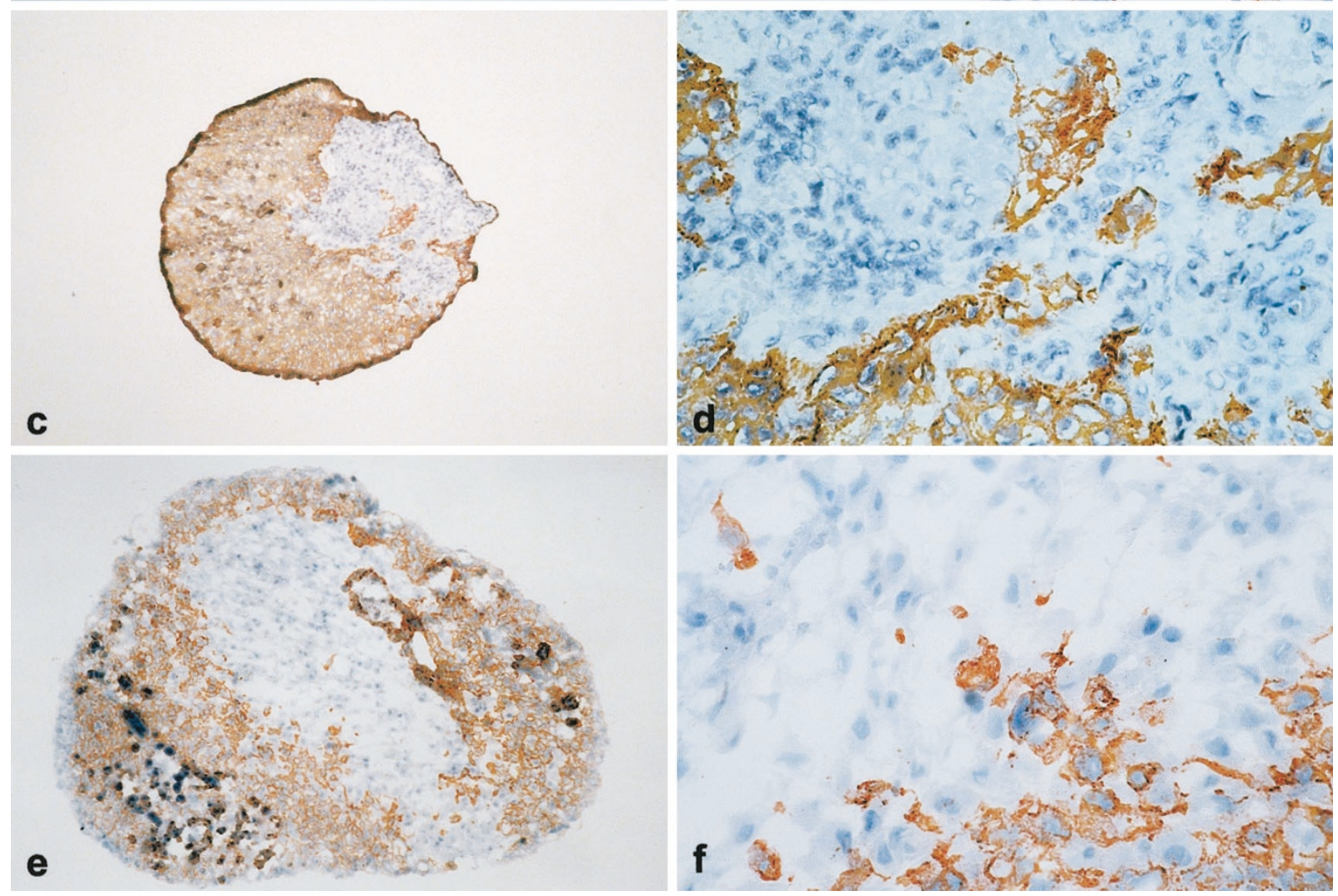

Figure 3.

Cryostat sections from confrontation cultures of multicellular spheroids of Jeg-3 choriocarcinoma cells with rounded fragments of endometrial tissue. Staining with anti-human cytokeratin. a and b, After 2 days of cocultivation, both confrontation partners are firmly attached to each other, and the first choriocarcinoma cells start to invade. $c$ and d, After 4 days of cocultivation, Jeg-3 choriocarcinoma cells protrude various fingers into the host tissue. e and f, After 6 days of cocultivation, a few single cells have already invaded deeply into the endometrial tissue fragment. Original magnification: $a, c$, and e, $\times 250$; b, $d$, and f, $\times 1000$.

cells toward the tumor component (Fig. 4b). BeWo cells themselves were negative for CD56. Several $\mathrm{CD}^{+} 6^{+}$cells within the decidual tissue component were able to proliferate in culture without any exogenous stimulus (Fig. 4c). The expression of perforin by decidual lymphocytes was maintained in tissue culture over more than 1 week. Perforin ${ }^{+}$cells were even found between the choriocarcinoma cells (Fig. 4d).

\section{Discussion}

Our data demonstrate that at least some aspects of the complex process involved in embryo implantation and trophoblast invasion can be imitated in vitro under suitable experimental conditions. Confrontation cultures of endometrial or decidual tissue fragments with multicellular spheroids of choriocarcinoma cells as a model of the invasive trophoblast closely resemble the in vivo conditions and provide an appropriate in vitro model for studying the interactions of NK-lineage cells present in the uterine mucosa with invasive choriocarcinoma cells. In current studies, choriocarcinoma cells must replace trophoblast cells in the threedimensional model of trophoblast invasion because it is not easy to find more or less permanent trophoblast 

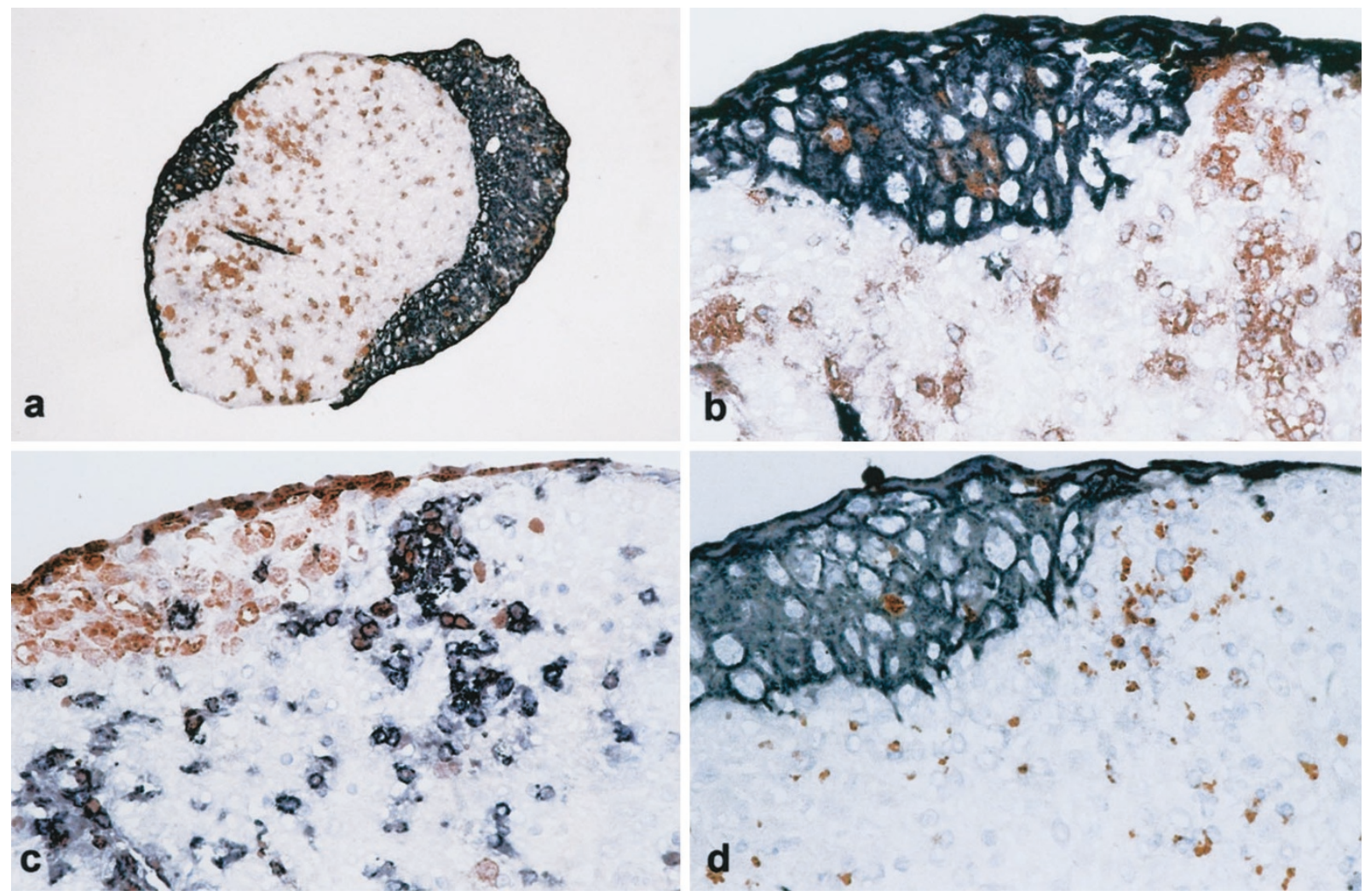

Figure 4.

Cryostat sections from confrontation cultures of multicellular spheroids of BeWo choriocarcinoma cells with rounded fragments of first-trimester decidual tissue. Embedding after 4 days. a and b, Double-staining with anti-human cytokeratin (black) and anti-human CD56 (red). Numerous CD56 ${ }^{+}$cells are present in the decidual component of the coculture, and a few $\mathrm{CD}_{6}{ }^{+}$NK cells are found between the BeWo choriocarcinoma cells. c, Double-staining with anti-human CD56 (black) and anti-human Ki-67 (red). Several $\mathrm{CD}^{+} 6^{+}$cells coexpress the Ki-67 antigen indicating cell proliferation. d, Double-staining with anti-human cytokeratin (black) and anti-human perforin (red). Some cells that have migrated into the BeWo component of the confrontation culture contain the cytolytic granule protein perforin. Original magnification: $a, \times 250$; $b$ to $d, \times 1000$.

cell lines. Most of the isolated trophoblast cells cannot be cultivated for a long period of time, the cells do not replicate well in vitro, and for the formation of multicellular spheroids, a high cell number is required. Using the three-dimensional tissue culture model, uterine lymphocytes can be examined within their natural environment, and no isolation procedure, possibly changing their cell-surface phenotype, is necessary. Moreover, they are able to proliferate within endometrial and decidual tissue fragments without any exogenous activation or stimulation by cytokines, as demonstrated by double-labeling with anti-CD56 and anti-Ki-67. In contrast, in vitro proliferation of isolated decidual NK cells was only achieved by costimulation with decidual stromal cells and a suboptimal dose of IL-2 or IL-15 (King et al, 1999). This was evidence that cell-cell contacts between NK cells and decidual stromal cells, which exist in the tissue culture model, were required. The molecular nature of the NK cell stimulatory response is not yet totally clear. Various progesterone-dependent stromal cell factors, as well as cytokines, eg, IL-15, are likely to be important in the regulation of decidual NK cell functions. Ligation of CD94, a receptor present on all CD56 ${ }^{+}$ decidual NK cells (Verma et al, 1997), resulted in a significant up-regulation of NK cell proliferation in response to IL-2 or IL-15 (Voss et al, 1998). A possible mechanism involved in the regulation of NK cell proliferation may be the interaction of the CD94 receptor complex with HLA-E, expressed on decidual stromal cells.

After cultivation, there was a drop in the expression of CD56 and perforin by uterine lymphocytes, although a few of the uterine NK cells retained their capacity to proliferate. The decrease in $\mathrm{CD}^{2} 6^{+}$cells was considerably less evident in decidual tissue fragments compared with endometrial tissue fragments. A drop in the number of perforin ${ }^{+}$cells after cultivation seems to be a common phenomenon and has already been shown with isolated decidual lymphocytes (Strbo et al 1999). Generally, fragments of decidual tissue may be more suitable for studies on trophoblast invasion than endometrial tissue fragments because their tissue architecture, the hormonal starting conditions, and the population of immunocompetent cells present in the cultivated decidual tissue resemble the in vivo conditions more closely than that of nonpregnant endometrial tissue. For invasion experiments, however, only tissue derived from decidua parietalis can be used to avoid trophoblast invasion before the experiment. A comparison of decidua basalis and decidua parietalis did not reveal any differences in lymphoid cells in either tissues. CD56 ${ }^{+}$NK cells were found in comparable distribution and numbers (Haller 
et al, 1995), and activated lymphocytes containing perforin were demonstrated in both decidua basalis and decidua parietalis (Rukavina et al, 1995), which justifies the use of decidua parietalis for the invasion experiments.

Our modified method of cocultivation using small silicon funnels enabled the formation of confrontation cultures under satisfactory nutrient supply and prevented the often observed drying-out of the cultures during the critical first hours of attachment. The adhesion rates of both Jeg-3 and BeWo choriocarcinoma multicellular spheroids to precultured fragments of endometrial or decidual tissue were more than $90 \%$ and were, therefore, significantly increased compared with data obtained by Grümmer et al (1994), who were applying another method for confrontation cultures.

In our experiments, Jeg-3 cells were more invasive than BeWo cells, confirming previous results (Grümmer et al, 1994). Nevertheless, BeWo cells were assumed to resemble normal trophoblast cells more closely than Jeg-3 and JAr cells (Hohn et al, 1998). The relatively low in vitro invasiveness of Jeg-3 and BeWo cells may be due to the lack of the production of the matrix-degrading enzymes, the matrix metalloproteinases MMP-2 and MMP-9, which were under the detectable limit as determined by zymography $(P$ Bischof, unpublished data). BeWo cells were also unable to invade basement membrane Matrigel. This property was considered to be due to the lack of production of MMP-9 (Morgan et al, 1998).

In general, in most trophoblast invasion experiments, basement membrane Matrigel was used as a substrate of invasion (eg, Damsky et al, 1994; Morgan et al, 1998; Zygmunt et al, 1998). Although this system provides reproducible data under standard experimental conditions, this acellular system is not suitable for studies of the interactions of particular cells present in the uterine environment. On sections of the implantation site of the first trimester decidua, CD56 ${ }^{+}$ cells were found intimately associated with the invading trophoblast (Allavena et al, 1991; Loke and King, 1995). Immunohistochemical double-staining of confrontation cultures demonstrated numerous CD56 ${ }^{+}$ cells directly at the invasion front of both Jeg-3 and BeWo choriocarcinoma cells. Some $\mathrm{CD}^{+} 6^{+}$cells were also found within the tumor component, indicating a migration of these cells from the endometrial or decidual tissue fragment toward the tumor component of the confrontation culture. The capability of NK cells to move across monolayers of endothelial cells derived from umbilical veins was shown previously (Bianchi et al, 1993). Moreover, an in vitro migration of IL-2activated NK cells in the intercellular space of spheroid tumors was already observed in the $\mathrm{H}-2$ glioma (Jääskeläinen et al, 1992). The authors supposed that one adhesion pathway, in particular the interaction of CD11/CD18 with CD54 (intercellular adhesion molecule-1), is involved in this complex process. Uterine NK cells within the cultured endometrial and decidual tissue fragments expressed CD11a/CD18, whereas endometrial and decidual stromal cells, as well as the BeWo choriocarcinoma cells, expressed
CD54 (intercellular adhesion molecule-1), adhesion molecules for cell-cell interactions (data not shown). Thus, uterine NK cells migrating toward the invasion front and within the multicellular aggregates of the choriocarcinoma cells may use this pathway as well. The migration of NK cells within the fibronectin- and laminin-rich extracellular matrix of cultivated endometrial and decidual tissue fragments may also involve integrins such as fibronectin and/or laminin receptors, which are expressed by uterine NK cells (Burrows et al, 1993). The nature of the chemoattractant guiding the NK cells in the direction of the tumor cells, however, is still unknown.

Some uterine lymphocytes found between the choriocarcinoma cells contained the cytolytic granule protein perforin, indicating that they are capable of effector functions. At least some of those cells retained the perforin and were not degranulated although they were in close contact with their targets. The results are in accord with previous data showing that, without any activation by IL-2, isolated decidual large granular lymphocytes show neither NK activity against normal trophoblast nor against Jeg-3 choriocarcinoma cells (King and Loke, 1990). The expression of perforin is regulated by decidual macrophages, which are important sources of cytokines (Hunt and Robertson, 1996; Sotosek et al, 1999). During normal pregnancy, uterine lymphocytes are under stringent control and do not make use of their effector functions. Because malignant trophoblast cells are killed by activated lymphocytes more easily than their normal counterparts (King and Loke, 1990), perforin may be implicated in the control of unduly invasive or malignant trophoblast populations in pathological pregnancies. The mechanisms regulating the recruitment of perforin in NK cells is still a matter of speculation. The use of confrontation cultures of endometrial or decidual tissue fragments with choriocarcinoma cells may help to answer at least some of the questions.

In conclusion, our data indicate that the threedimensional tissue culture model composed of rounded fragments of endometrial or decidual tissue and multicellular spheroids of choriocarcinoma cells enables the study of dynamic processes during trophoblast invasion at the experimental level. The system shows a migration of perforin-containing CD56 ${ }^{+}$ uterine lymphocytes toward potential target cells, thus demonstrating the infiltrative capacity of $\mathrm{CD}^{+} 6^{+}$uterine NK cells. Moreover, using this tissue culture method, the roles of cytokines and growth factors in the regulation of lymphocyte migration and/or trophoblast invasion can be tested on an experimental model that resembles the in vivo conditions more closely than other systems.

\section{Materials and Methods}

\section{Endometrial and Decidual Tissue}

Human mid-secretory endometrium, derived from uteri of women with a regular cycle of 28 days, was used. The tissue, removed under sterile conditions by 
means of curettages for diagnostic reasons, was obtained by the Krankenhaus der Barmherzigen Brüder, Graz, Austria. The procedure has been approved by the local Ethical Committee, which is affiliated with the hospital. One part of the tissue fragments was prepared for routine histology to exclude pathological changes and to determine the luteal phase of the endometrium (Noyes and Hertig, 1955). In addition, samples were dated according to the last menstrual period (by means of direct inquiry). The other part of the tissue was processed for tissue culture.

The tissue was cut into pieces of about $800 \mu \mathrm{m}$ under a dissecting microscope equipped with an ocular grid, transferred to $25-\mathrm{ml}$ glass spinner flasks, and stirred at about $90 \mathrm{rpm}$ using a magnetic stirrer system (IKA-Werk, Staufen, Germany) in a humidified $\mathrm{CO}_{2}$ incubator. The culture medium (DMEM; PAA Laboratories, Linz, Austria) was supplemented with $10 \%$ fetal calf serum (BioWhittaker Europe, Verviers, Belgium), antibiotics (PAA Laboratories), $10 \mathrm{ng} / \mathrm{ml}$ progesterone, $10 \mathrm{ng} / \mathrm{ml}$ gestonoroncaproate, and 300 $\mathrm{pg} / \mathrm{ml} 17-\beta$-estradiol. The hormones (kindly provided by Dr. Neumann, Schering, Berlin, Germany) were included in the culture medium to maintain the luteal phase of the endometrial tissue (Hohn et al, 1998) and to mimic the in vivo conditions during gestation. The medium was changed daily, and the tissue fragments were stirred for 3 to 6 days. The cultivated tissue fragments were embedded in tissue-freezing medium (Tissue Tek OCT-compound; Sakura Finetek USA, Inc., Torrance, California). Serial 3- $\mu \mathrm{m}$ cryostat sections were collected on glass slides, air-dried for 2 hours at room temperature, and stored at $-40^{\circ} \mathrm{C}$ until required.

In addition to endometrium, first trimester decidual tissue, derived from the decidua parietalis (kindly provided by the Department of Obstetrics and Gynecology, University Hospital, Graz, Austria) was used. Decidua basalis had to be excluded, because invasive trophoblast cells may be found within the tissue before confrontation with choriocarcinoma cells. One part of the tissue was immediately embedded in tissue-freezing medium. Cryostat sections $(3-\mu \mathrm{m})$ were stained with anti-human cytokeratin (clone MNF116) to exclude trophoblast invasion in the tissue material used for confrontation cultures.

\section{Multicellular Spheroids of Choriocarcinoma Cells}

The human choriocarcinoma cell lines Jeg-3 (Köhler and Bridson, 1971; kindly provided by $\operatorname{Dr} \mathrm{R}$ Grümmer, Department of Anatomy, University of Essen, Essen, Germany) and BeWo (Patillo and Gey, 1968; obtained from the American Type Culture Collection, Rockville, Maryland), were maintained in DMEM supplemented with $10 \%$ fetal calf serum and antibiotics. Exponentially growing monolayers were gently detached by Accutase (Innovative Cell Technologies, San Diego, California; supplied by PAA Laboratories). The resulting single-cell suspension was cultivated in petri dishes with nonadherent surfaces to form multicellular aggregates. After a cultivation period of 2 days, the round-shaped cell aggregates were transferred into $50-\mathrm{ml}$ glass spinner flasks and stirred at about $90 \mathrm{rpm}$ for at least 3 days. Multicellular spheroids with a diameter of $300 \mu \mathrm{m}$ were selected under a dissecting microscope equipped with an ocular grid.

\section{Confrontation Cultures of Rounded Fragments of Human Endometrial or Decidual Tissue with Multicellular Spheroids of Choriocarcinoma Cells}

A new method was used for confrontation cultures of endometrial or decidual tissue fragments, $800 \mu \mathrm{m}$ in diameter, with multicellular spheroids of choriocarcinoma cells (Fig. 5).

In brief, after 3 days in spinner culture, the rounded endometrial or decidual tissue fragments were transferred into small funnels inserted in silicon pads. Multicellular spheroids of choriocarcinoma cells were selected for $300 \mu \mathrm{m}$ in diameter and set in close contact with those endometrial or decidual tissue fragments in the funnels (Fig. 6). The confrontation cultures were covered with a small drop of complete culture medium and incubated for at least 24 hours in a humidified $\mathrm{CO}_{2}$ incubator. This incubation period was required to form stable contacts between both confrontation partners. The drop of culture medium prevented the drying out of the cultures and provided a satisfactory supply with nutrients during the first hours of adhesion. After the establishment of stable contacts, the confrontation cultures were transferred into petriPERM petri dishes with a hydrophobic surface (Kendro Laboratory Products, Wien, Austria) and cultivated for another 24 hours. Thereafter, the contact between both confrontation partners was stable enough for further cultivation in 25-ml spinner flasks and stirring at approximately $90 \mathrm{rpm}$. The culture medium was changed daily. After 2 to 6 days, confrontation cultures were embedded in tissue-freezing medium as described above and processed for immunohistochemistry.

\section{Immunohistochemistry}

Cryostat sections $(3-\mu \mathrm{m})$ from confrontation cultures were thawed, air-dried, and fixed in acetone for $5 \mathrm{~min}-$ utes at room temperature. After rinsing in tris-buffered solution (TBS), $\mathrm{pH} 7.2$, containing $5 \%$ newborn calf serum, the endogenous peroxidase activity was blocked by incubation in the peroxidase-blocking solution (Dako, Glostrup, Denmark) for 5 minutes. Thereafter, the sections were incubated with the appropriate concentrations of the primary antibodies for 30 minutes at room temperature, rinsed thoroughly in TBS, and exposed to the horseradish peroxidase-labeled streptavidin biotin (LSAB+/HRP) visualization system (Dako) following the manufacturer's instructions. The peroxidase was developed with 3-amino-9-ethyl-carbazole/dimethylformamide (AEC; Sigma, Vienna, Austria) in acetate buffer in the dark for 4 minutes. The reaction was stopped by rinsing in distilled water. The sections were counterstained with Mayer's hemalum and mounted with Kaiser's glycerol gelatin (Merck, Vienna, Austria). 


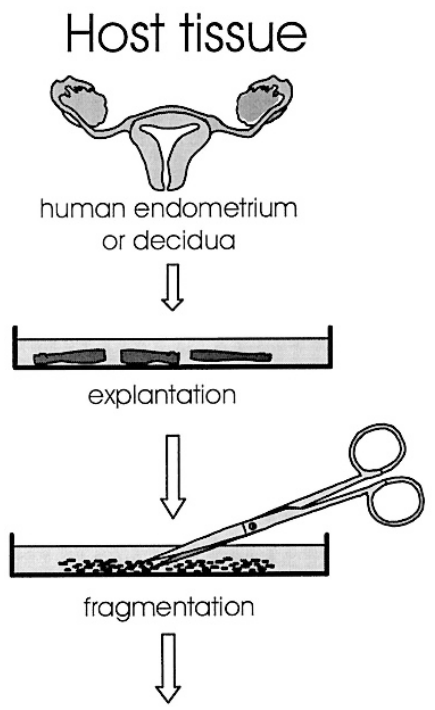

\section{Choriocarcinoma cells}

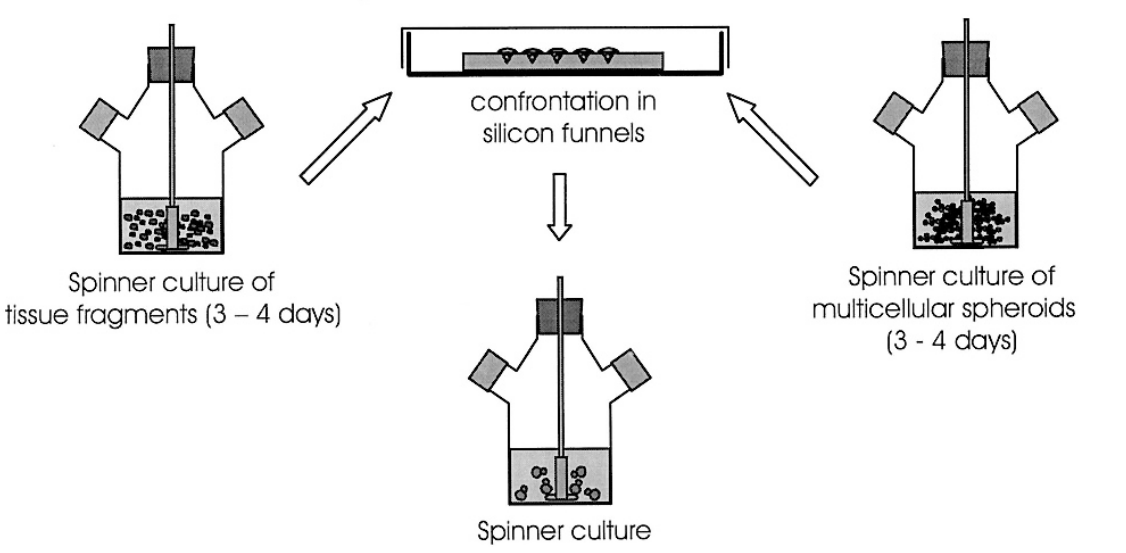

Figure 5.

Experimental procedure for confrontation of endometrial or decidual tissue fragments with multicellular spheroids of choriocarcinoma cells.

For double labeling, the LSAB+/HRP visualization system was followed by the alkaline phosphatase antialkaline phosphatase (APAAP) system (Dako). For this purpose, the sections were incubated with levamisole for 10 minutes to block the endogenous alkaline phosphatase, rinsed in TBS, and incubated with the second primary antibody for 30 minutes at room temperature. Thereafter, the sections were exposed to a rabbit antimouse antibody (1:25) for 30 minutes, rinsed in TBS, and incubated with the APAAP (1:50). After rinsing in TBS, the alkaline phosphatase was developed with 5-bromo4-chloro-3-indolyl phosphate/nitro blue tetrazolium (BCIP/NBT, Dako) under microscopical control. The reaction was stopped by rinsing in distilled water. The sections were counterstained with Mayer's hemalum and mounted with Kaiser's glycerol gelatin.

The antibodies used are as follows:

mouse anti-human CD 56 (Becton Dickinson, San Jose, California) 1:50

mouse anti-human cytokeratin (clone MNF116,

Dako) 1:100

mouse anti-human perforin (Pharmingen, San Diego, California) 1:500

mouse anti-human Ki-67 (Dako) 1:400.
Negative controls were performed by substitution of the primary antibody with normal mouse serum (IgG fraction), with mouse IgG1 (for CD56, cytokeratin, and $\mathrm{Ki}-67)$, or with lgG2b (for perforin) as isotype controls. Photographs were taken using an Axiophot microscope (Zeiss, Oberkochen, Germany).

\section{Automated Image Analysis}

The amount of total tissue and tissue stained by immunohistology has been determined using tissuecounter analysis as described previously (Smolle, 2000). In brief, the histological slide was overlaid with regularly placed square measurement masks of equal size, and the gray level, color, and texture information within each element were recorded. In a learning set, the elements were labeled interactively by the user and classified according to representing "background" (area of the slide not covered by the tissue), "negative tissue" (tissue not containing immunohistologically stained material), and "positive tissue" (tissue containing immunohistologically stained material). Entire sections of freshly excised tissue material and cultivated rounded tissue fragments were scanned 


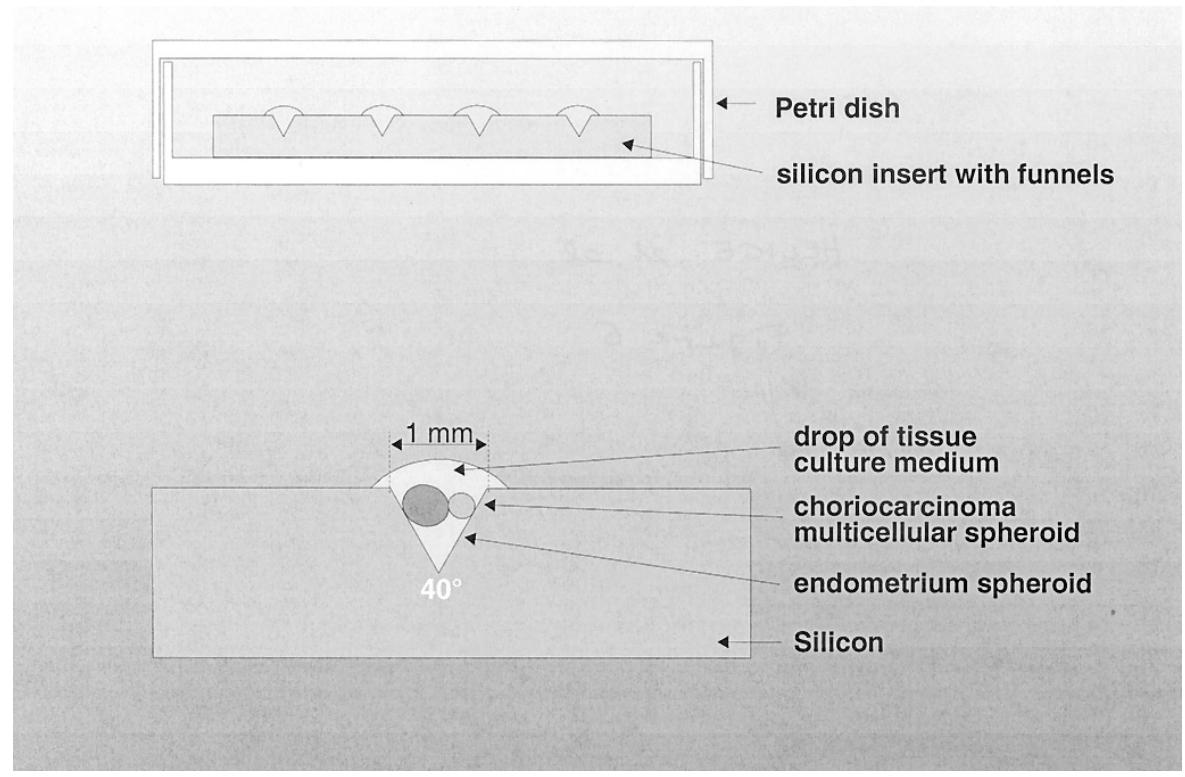

Figure 6.

Schematic presentation of the culture conditions of the confrontation cultures during the first hours of attachment.

using an Axioplan 2 bright field microscope (Zeiss) mounted with an automated scanning table. Scanning was performed with a $\times 40$ objective. The system was connected to a KS 4003.0 image analysis unit (Kontron, Munich, Germany). For each section, the proportion of "positive tissue" elements in relation to the total number of tissue elements was recorded.

\section{Acknowledgements}

We thank Mrs. Astrid Blaschitz for precious hints concerning immunohistochemistry and Mr. Rudolf Schmied for the layout of the figures. We are most grateful to Dr. Elke Gruber-Fröhlich, Dr. Elmar Holzer, and Dr. Angelika Köhldorfer, Krankenhaus der Barmherzigen Brüder, Graz, for kindly providing the endometrial tissue and to Dr. Wolfgang Walcher, Department of Obstetrics and Gynecology, University of Graz, for providing the decidual tissue material.

\section{References}

Allavena P, Paganini C, Martin-Padura I, Peri G, Gaboli M, DeJana E, Marchisio PC, and Mantovani A (1991). Molecules and structures involved in the adhesion of natural killer cells to vascular endothelium. J Exp Med 173:439-448.

Bersinger NA, Sinosich MJ, Baber R, Torode H, and Saunders DM (1993). Trophoblast-endometrium co-cultures as a means of assessment of endometrial readiness for implantation. Trophoblast Res 7:211-222.

Bianchi G, Sironi M, Ghibaudi E, Selvaggini C, Elices M, Allavena P, and Mantovani A (1993). Migration of natural killer cells across endothelial cell monolayers. J Immunol 151: 5135-5144.

Bulmer JN, Morrison L, Longfellow M, Ritson A, and Pace D (1991). Granulated lymphocytes in human endometrium: Histochemical and immunohistochemical studies. Hum Reprod 6:791-798.
Burrows TD, King A, and Loke YW (1993). Expression of adhesion molecules by human decidual large granular lymphocytes. Cell Immunol 147:81-94.

Damsky CH, Librach C, Lim KH, Fitzgerald ML, McMaster MT, Janatpour M, Zhou Y, Logan SK, and Fisher SJ (1994). Integrin switching regulates normal trophoblast invasion. Development 120:3657-3666.

Deniz G, Christmas SE, and Johnson P (1996). Soluble mediators and cytokines produced by human $\mathrm{CD}^{-}$leucocyte clones from decidualized endometrium. Immunology 87:92-98.

Grümmer R, Hohn H-P, and Denker H-W (1990). Choriocarcinoma cell spheroids: An in vitro model for the human trophoblast. Trophoblast Res 4:97-111.

Grümmer R, Hohn H-P, Mareel MM, and Denker H-W (1994). Adhesion and invasion of three human choriocarcinoma cell lines into human endometrium in a three-dimensional organ culture system. Placenta 15:411-429.

Gudelj L, Christmas SE, Laskarin G, Johnson PM, Podack ER, and Rukavina D (1997). Membrane phenotype and expression of perforin and serine esterases by $\mathrm{CD}^{-}$peripheral blood and decidual granular lymphocyte-derived clones. Am J Reprod Immunol 38:162-167.

Gudelj L, Deniz G, Rukavina D, Johnson PM, and Christmas SE (1996). Expression of functional molecules by human $\mathrm{CD}^{-}$decidual granular leukocyte clones. Immunology 87 : 609-615.

Haller H, Tedesco F, Rukavina D, Radillo O, Gudelj L, and Beer AE (1995). Decidual trophoblast interactions: Decidual lymphoid cell populations in basal and parietal decidua. J Reprod Immunol 42:71-75.

Hamilton GS, Lysiak JJ, Han VKM, and Lala PK (1998). Autocrine-paracrine regulation of human trophoblast invasiveness by insulin-like growth factor (IGF)-II and IGF-binding protein. Exp Cell Res 244:147-156. 
Hohn H-P, Linke M, Ugele B, and Denker H-W (1998). Differentiation markers and invasiveness: Discordant regulation in normal trophoblast and choriocarcinoma cells. Exp Cell Res 244:249-258.

Hunt JS and Robertson SA (1996). Uterine macrophages and environmental programming for pregnancy. J Reprod Immunol 31:1-25.

Jääskeläinen J, Mäenpää A, Patarroyo M, Gahmberg CG, Somersalo K, Tarkkanen J, Kallio M, and Timonen T (1992). Migration of recombinant IL-2-activated $\mathrm{T}$ and natural killer cells in the intercellular space of human $\mathrm{H}-2$ glioma spheroids in vitro. J Immunol 149:260-268.

Jokhi PP, King A, and Loke YW (1997). Cytokine production and cytokine receptor expression by cells of the human first trimester placental-uterine interface. Cytokine 9:126-137.

King A (2000). Uterine leukocytes and decidualization. Hum Reprod Update 6:28-36.

King A, Balendran N, Woodings P, Carter NP, and Loke YW (1991). CD3 ${ }^{-}$leukocytes present in human uterus during early placentation: Phenotypic and morphologic characterization of the CD56 ${ }^{++}$population. Dev Immunol 1:169-190.

King A, Burrows T, Verma S, Hiby S, and Loke YW (1998). Human uterine lymphocytes. Hum Reprod Update 4:480485.

King A, Gardner L, and Loke YW (1999). Co-stimulation of human decidual natural killer cells by interleukin-2 and stromal cells. Hum Reprod 14:656-663.

King A and Loke YW (1990). Human trophoblast and JEG choriocarcinoma cells are sensitive to lysis by IL-2stimulated decidual NK cells. Cell Immunol 129:435-448.

King A, Wellings V, Gardner L, and Loke YW (1989). Immunocytochemical characterization of the unusual large granular lymphocytes in the human endometrium throughout the menstrual cycle. Hum Immunol 24:195-205.

King A, Woodings P, Gardner L, and Loke YW (1993). Expression of perforin, granzyme $A$ and $\mathrm{TIA}-1$ by human uterine $\mathrm{CD}^{+} 6^{+} \mathrm{NK}$ cells implies they are activated and capable of effector functions. Hum Reprod 8:2061-2067.

Kliman HJ, Feinberg RF, and Haimowitz JE (1990). Human trophoblast-endometrial interactions in an in vitro suspension culture system. Placenta 11:349-367.

Köhler PO and Bridson E (1971). Isolation of hormoneproducing clonal lines of human choriocarcinoma. J Clin Endocrinol Metab 32:683-687.

Lin PY, Joag SV, Young JDE, Chang YS, Soong YK, and Kuo TT (1991). Expression of perforin by natural killer cells within first trimester endometrium in humans. Biol Reprod 45:698703.

Lindenberg S, Nielsen MH, and Lenz S (1985). In vitro studies of human blastocyst implantation. Ann NY Acad Sci 442: 368-374.

Loke YW and King A (1995). Human implantation. Cell biology and immunology. Cambridge: Cambridge University Press, 102-129.
Mareel MM, Kint J, and Meyvisch C (1979). Methods of study of the invasion of malignant $\mathrm{C} 3 \mathrm{H}$-mouse fibroblasts into embryonic chick heart in vitro. Virchow's Arch B Cell Pathol 30:95-111.

Morgan M, Kniss D, and McDonnell S (1998). Expression of metalloproteinases and their inhibitors in human trophoblast continuous cell lines. Exp Cell Res 242:18-26.

Noyes RW and Hertig AT (1955). Dating the endometrial biopsy. Fertil Steril 1:3-25.

Patillo RA and Gey GO (1968). The establishment of a cell line of human hormone-synthesizing trophoblastic cells in vitro. Cancer Res 28:1231-1236.

Rukavina D, Rubesa G, Gudelj L, Haller H, and Podack ER (1995). Characteristics of perforin expressing lymphocytes within the first trimester decidua of human pregnancy. Am J Reprod Immunol 33:394-404.

Smolle J (2000). Computer recognition of skin structures using discriminant and cluster analysis. Skin Res Technol 6:58-63.

Sotosek V, Laskarin G, Strbo N, Dohr G, Blaschitz A, Podack ER, and Rukavina D (1999). Decidual macrophages are the population of decidual adherent cells which regulates perforin expression in cytolytic cells. Am J Reprod Immunol 42:76-82.

Starkey PM, Sargent IL, and Redman CWG (1988). Cell populations in human early pregnancy decidua: Characterization and isolation of large granular lymphocytes by flow cytometry. Immunology 65:129-134.

Strbo N, Laskarin G, Sotosek V, Randic LJ, Podack ER, and Rukavina D (1999). Modulation of perforin expression in the decidual and peripheral blood cytotoxic lymphocytes in culture. Am J Reprod Immunol 42:14-21.

Verma S, King A, and Loke YW (1997). Expression of killercell inhibitory receptors (KIR) on human uterine NK cells. Eur J Immunol 27:979-983.

Vicovac L, Jones CJ, and Aplin JD (1995). Trophoblast differentiation during formation of anchoring villi in a model of the early human placenta in vitro. Placenta 16:41-56.

Vicovac L, Papic N, and Aplin JD (1993). Tissue interactions in first trimester trophoblast - decidua co-cultures. Trophoblast Res 7:223-236.

Voss SD, Daley J, Ritz J, and Robertson MJ (1998). Participation of the CD94 receptor complex in costimulation of human natural killer cells. J Immunol 160:1618-1626.

Zygmunt M, Hahn D, Kiesenbauer N, Munstedt K, and Lang $U$ (1998). Invasion of cytotrophoblastic (JEG-3) cells is upregulated by interleukin-15 in vitro. Am $\mathrm{J}$ Reprod Immunol 40:326-331. 